\title{
Granulação natural em reator operado em bateladas sequenciais: características dos grânulos e desempenho no tratamento de esgoto sanitário
}

\author{
Natural granulation in sequencing batch reactor: granules \\ characteristics and performance for domestic wastewater treatment \\ Jéssica Antunes Xavier ${ }^{1 *} \oplus$, Lorena Bittencourt Guimarães ${ }^{1} \oplus$, Wanderli Rogério Leite ${ }^{2} \oplus$, \\ Cláudia Lavina Martins', Gilberto Caye Daudt ${ }^{1} \oplus$, Rejane Helena Ribeiro da Costa' ${ }^{1}$
}

口-

\section{RESUMO}

Os reatores operados em bateladas sequenciais (RBS) com biomassa granular aeróbia são uma tecnologia compacta e promissora no tratamento de águas residuárias. Porém, sua utilização com esgoto sanitário ainda é um desafio, devido à instabilidade e desintegração dos agregados. O presente trabalho avaliou a granulação da biomassa em um RBS em escala piloto, sem a adição de inóculo, para o tratamento de esgoto sanitário. O estudo foi dividido em três estratégias operacionais com ciclos compostos pelas fases: enchimento, anóxica, aeróbia, sedimentação, descarte e repouso. Trabalhou-se com variações no tempo dos ciclos, 4 horas (estratégias I e II) e 6 horas (estratégia III), e na fase anóxica, 13, 30 e 90 minutos nas estratégias I, II e III, respectivamente. O desenvolvimento dos grânulos ocorreu de forma natural, sem inoculação, e o reator tratou o esgoto sanitário atendendo às exigências nacionais de padrões de lançamento de efluentes. As características do lodo granular aeróbio e o desempenho do reator no tratamento de esgoto melhoraram com o aumento da fase anóxica. Grânulos (200 a 400 m) compreenderam mais de 80\% da biomassa com boas características de sedimentabilidade (a razão entre os índices volumétricos de lodo após 30 e 10 minutos de sedimentação - IVL $\mathrm{L}_{30} / \mathrm{IVL}_{10}$ esteve entre 0,7 e 1,0) na estratégia III. As variáveis de maior relevância no processo foram a razão $I V L_{30} / I V L_{10}$ e a razão entre a demanda química de oxigênio solúvel do efluente e do anóxico ( $\mathrm{DQO}_{\mathrm{s}}$ efluente/ $\mathrm{DQO}_{\mathrm{s}}$ anóxico), polissacarídeos e temperatura, indicando a importância desses parâmetros para a manutenção da estabilidade operacional de um RBS com grânulos.

Palavras-chave: granulação aeróbia natural; reator em bateladas sequenciais; tratamento de esgoto sanitário.

\begin{abstract}
Sequencing batch reactor (SBR) with aerobic granular biomass is a compact and promising technology in wastewater treatment. However, its use for sanitary sewage is still a challenge due to the instability and disintegration of the aggregates. The present work evaluated the biomass granulation in a pilot SBR, without addition of inoculum, for sanitary sewage treatment. The study was divided into three operational strategies with cycles composed by the phases of: filling, anoxic, aerobic, settling, effluent withdrawal and idle. The variations in the operational cycle time were: 4 hours (strategies I and II) and 6 hours (strategy III); and anoxic phase of 13, 30 and 90 minutes in strategies I, II and III, respectively. The granules development occurred in a natural way, without inoculation, and the reactor treated the sanitary wastewater meeting the national requirements of effluent discharge standards. The characteristics of the aerobic granular sludge and the reactor's performance improved with the anoxic phase increase. Granules (200-400 $\mu \mathrm{m}$ ) were more than $80 \%$ of the biomass with good sedimentation characteristics $\left(\mathrm{SVI}_{30} / \mathrm{SVI}_{10}\right.$ ratio between 0.7-1.0), in strategy III. The greatest relevance variables for the process were $\mathrm{SVI}_{30} / \mathrm{SVI}_{10}$ and COD Effluent/COD $\mathrm{S}$ Anoxic ratios, polysaccharides and temperature, indicating the importance of these parameters for the maintenance of the operational stability of granular SBR.
\end{abstract}

Keywords: natural aerobic granulation; sequencing batch reactor; sanitary sewage treatment. 


\section{INTRODUÇÃO}

A busca por tecnologias de tratamento de efluentes mais compactas, com remoção simultânea de matéria orgânica e de nutrientes, torna-se indispensável ante a crescente expansão demográfica. Uma das tecnologias de tratamento biológico em recente desenvolvimento é a de biomassa granular aeróbia. Essa tem se mostrado muito atrativa, visto as inúmeras vantagens dos grânulos aeróbios em comparação aos flocos dos sistemas convencionais de lodos ativados, dentre as quais, citam-se: melhor sedimentabilidade, remoção simultânea de fósforo e nitrogênio e capacidade de suportar variações de cargas orgânicas (ZHU et al., 2013).

O grânulo aeróbio é um agregado microbiano compacto com estrutura bem definida. Comparado com um floco biológico de um reator de lodos ativados, os grânulos apresentam-se mais fortes, regulares e densos, possuem elevada retenção de biomassa, excelente sedimentabilidade e elevada atividade microbiana (MORGENROTH et al., 1997). São preferencialmente cultivados em reatores operados em bateladas sequenciais (RBS), os quais dispensam o uso de decantadores, bem como o retorno de lodo ao reator biológico, tornando o sistema mais compacto, requerendo menor área para implantação. Por apresentarem estrutura compacta, com diâmetro variando entre 0,2 e 3,0 mm, os grânulos aeróbios têm resistência à transferência de massa, especialmente de oxigênio. Dessa forma, resultam na limitação da difusão de oxigênio internamente, e zonas aeróbias, anóxicas e anaeróbias podem existir dentro dos grânulos, favorecendo condições ambientais para o crescimento de bactérias aeróbias e facultativas, possibilitando a remoção simultânea de carbono, nitrogênio e fósforo (DE KREUK; KISHIDA; VAN LOOSDRECHT, 2007).

O índice volumétrico de lodo (IVL) é um parâmetro cuja medição está diretamente relacionada com a capacidade de retenção da biomassa e com a separação sólido-líquido no reator. Segundo Zheng, Yu e Sheng (2005), esses valores são inferiores a $80 \mathrm{~mL} \cdot \mathrm{g}^{-1}$, podendo alcançar até $20 \mathrm{~mL} \cdot \mathrm{g}^{-1} \mathrm{em}$ sistemas de lodo granular. A quantidade e as componentes das substâncias poliméricas extracelulares (do inglês extracellular polymeric substances - EPS) também desempenham papel relevante nas características e na estabilidade dos grânulos aeróbios. As EPS influenciam diretamente no desempenho da agregação de lodos, nas características da superfície celular, na desidratação e na adsorção (WAN et al., 2013). A matriz polimérica pode conter proteínas, substâncias húmicas, ácidos nucleicos, glicoproteínas, fosfolipídios, etc. Porém, ainda não há informações conclusivas da proporção dos diferentes componentes das EPS, bem como do seu papel na granulação aeróbia (SARMA; TAY; CHU, 2017).

A velocidade de crescimento dos microrganismos tem sido demonstrada como um fator importante na formação de grânulos estáveis (DE KREUK \& VAN LOOSDRECHT, 2004). De acordo com Carta et al. (2001), os organismos heterotróficos apresentam velocidades de crescimento reduzidas quando se desenvolvem utilizando o substrato armazenado internamente (polihidroxibutirato - PHB), em comparação com o crescimento em substrato facilmente biodegradável, tal como acetato ou glicose. Em estudos anteriores com biomassa granular, esse fenômeno foi usado para obter uma granulação estável (DE KREUK \& VAN LOOSDRECHT, 2004).

A formação de grânulos que sejam capazes de nitrificar e acumular fósforo tem sido investigada nas últimas décadas com sucesso (PRONK et al., 2015). Além disso, muitos autores têm focado na caracterização da biomassa granular e nos diversos fatores ambientais e operacionais que afetam o mecanismo de formação de grânulos (LIU; YANG; TAY, 2004; SARMA; TAY; CHU, 2017). A granulação é influenciada pelas condições de partida do reator, como: inoculação (TAY; LIU; LIU, 2001), composição do substrato e carga orgânica (MORGENROTH et al., 1997), estratégia de alimentação, configuração do reator e características hidrodinâmicas (MOGHADDAM \& MOGHADDAM, 2015), tempo de estabilização (ADAV \& LEE, 2008), relação de troca e intensidade de aeração (YANG; TAY; LIU, 2003). Contudo, a aplicação de lodo granular aeróbio no tratamento de esgoto sanitário em grande escala ainda é um desafio. Na literatura há poucos estudos sobre a aplicação dessa tecnologia no tratamento de efluentes reais, ou seja, não sintéticos. A dificuldade de aplicação dessa tecnologia está ligada diretamente à instabilidade dos grânulos e à sua desintegração (WAN et al., 2013).

Nesse contexto, o presente trabalho pretende avançar no conhecimento do processo de granulação natural sem a adição de inóculo, isto é, na formação dos grânulos a partir do próprio esgoto sanitário real. Para esse fim, foram avaliadas as características físico-químicas e biológicas da biomassa granular aeróbia em um RBS em escala piloto, submetido a diferentes condições operacionais, com tempo da fase anóxica correspondendo a 5; 12 e 25\% do tempo total do ciclo.

\section{MATERIAIS E MÉTODOS}

\section{Sistema experimental}

O estudo foi conduzido em reator cilíndrico, construído em acrílico transparente, com volume útil de $98 \mathrm{~L}$ ( $0,25 \mathrm{~m}$ de diâmetro interno e $2,18 \mathrm{~m}$ de altura). O processo ocorreu em bateladas sequenciais, com troca volumétrica de 56\% e alimentação com efluente sanitário real. Introduziu-se ar comprimido por meio de um difusor de membrana localizado na parte inferior do reator. A vazão de ar foi mantida constante em 32 L.min ${ }^{-1}$, o que resultou em uma velocidade superficial de fluxo ascendente de $1,1 \mathrm{~cm} \cdot \mathrm{s}^{-1}$.

O start up do sistema ocorreu sem a necessidade de inoculação (granulação natural). O monitoramento foi iniciado quando a concentração de biomassa foi suficiente para caracterizar o reator como um sistema granular, ou seja, quando pelo menos $50 \%$ das partículas apresentaram diâmetro superior a 0,2 mm (DE KREUK; KISHIDA; VAN LOOSDRECHT, 2007). 
Os ciclos operacionais compreenderam às seguintes fases: enchimento, anóxica, aeração, sedimentação e descarte do efluente tratado. Durante o estudo, modificou-se a duração da fase anóxica, no intuito de selecionar os organismos acumuladores de fosfato (PAO) com o objetivo de melhorar a remoção de fósforo e também tornar o processo mais estável (ZHANG; ZHANG; YANG, 2015). A pesquisa foi dividida em três diferentes estratégias operacionais (Figura 1). Na estratégia I, o tempo de ciclo de 4 horas foi dividido nas seguintes fases: 3 minutos de alimentação; 13 minutos de período anóxico; 200 minutos de aeração contínua; 20 minutos de sedimentação; e 4 minutos de descarte do efluente. Na estratégia II, o tempo de ciclo se manteve em 4 horas, com alimentação de 3 minutos; 30 minutos de período anóxico; 183 a 188 minutos de aeração; 20 a 15 minutos de sedimentação; e 4 minutos de descarte de efluente. Durante a primeira semana de operação da estratégia II, o tempo de sedimentação foi progressivamente reduzido de 20 para 15 minutos para estimular a seleção dos grânulos. Na estratégia III, o tempo de ciclo passou para 6 horas, sendo distribuído da seguinte forma: 3 minutos de alimentação; 90 minutos de período anóxico; 248 minutos de aeração contínua; 15 minutos de sedimentação; e 4 minutos de descarte do efluente. Durante a estratégia III foram inseridos pulsos de ar, de forma a misturar o substrato com biomassa na fase anóxica. O tempo de operação das estratégias I, II e III foram 127, 115 e 108 dias, respectivamente.

\section{Métodos analíticos}

Os parâmetros de monitoramento do reator foram: demanda química de oxigênio solúvel $\left(\mathrm{DQO}_{\mathrm{S}}\right)$, demanda bioquímica de oxigênio $\left(\mathrm{DBO}_{5}\right)$, nitrogênio amoniacal $\left(\mathrm{N}-\mathrm{NH}_{4}^{+}\right)$, fosfato $\left(\mathrm{P}^{-} \mathrm{PO}_{4}{ }^{3-}\right)$, sólidos suspensos totais (SST) e sólidos suspensos voláteis (SSV), analisados de acordo com o Standard Methods (APHA; AWWA: WEF, 2005). O pH e a temperatura foram medidos in loco com sonda multiparâmetros (YSI pro1020).

\section{Características físico-químicas dos grânulos}

A distribuição do tamanho das partículas foi obtida por difração a laser (Malvern MasterSizer Series 2000, Malvern Instruments,

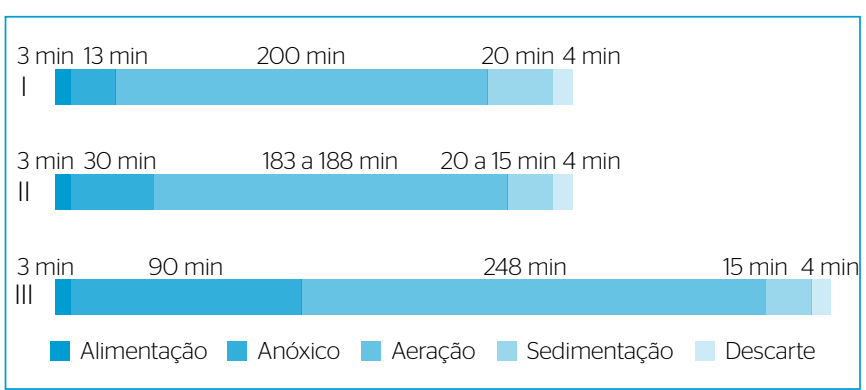

Figura 1 - Condições operacionais durante as estratégias I, II, III aplicadas no reator operado em bateladas sequenciais em escala piloto utilizando efluente sanitário.
Reino Unido), e a percentagem de grânulos foi determinada pelo método de peneiramento (BIN et al., 2011). A triagem foi realizada com três peneiras de aço inoxidável, com as respectivas malhas de abertura: 0,6; 0,4 e 0,2 $\mathrm{mm}$. Os índices volumétricos de lodo, $\mathrm{IVL}_{5}$, $\mathrm{IVL}_{10}, \mathrm{IVL}_{30}$, foram determinados medindo o volume de biomassa após 5, 10 e 30 minutos de sedimentação, respectivamente. O procedimento de extração de EPS foi realizado seguindo metodologia proposta por McSwain et al. (2005). As proteínas (PN) e os polissacarídeos (PS) foram determinados de acordo com Lowry et al. (1951) e Dubois et al. (1956), respectivamente.

\section{Características da comunidade microbiana}

A identificação da população bacteriana ativa foi realizada pela técnica de hibridização in situ por fluorescência (fluorescence in situ hibridization - FISH). As amostras foram fixadas com paraformaldeído a $4 \%$ e hibridizadas com sondas específicas (AMANN, 1995). As sondas identificadas com fluorocromos CY3 utilizadas foram: EUBmix (EUB338 I +II+III), NSO190 para as bactérias oxidantes de amônio do grupo $\beta$-Proteobacteria, NTSpa662 para membros do gênero Nitrospira, PAE997 para Pseudomonas sp., $\mathrm{PAO}_{\text {mix }}(462+651+846) \mathrm{e}$ $\mathrm{GAO}_{\text {mix }}(431+989)$ para organismos acumuladores de fósforo e glicogênio, respectivamente (GREUTER et al., 2016).

A dinâmica da população microbiana foi avaliada pelo sequenciamento de DNA de nova geração (Illumina MiSeq ${ }^{\circledR}$ ). O DNA foi extraído com o kit de extração MoBio PowerBiofilm ${ }^{\mathrm{Tw}}$ (MoBio Lab., Estados Unidos). A região rRNA 16S V3/V4 foi amplificada usando os iniciadores 341F (CCTACGGGRSGCAGCAG) e 806R(GGACTACHVGGGTWTCTAAT). O mapeamento foi conduzido utilizando BLASTN 2.2.28, em comparação ao banco de dados GreenGenes 13.8, tendo como referência as sequências do gene $16 \mathrm{~S}$ rRNA para atribuir as leituras das unidades taxonômicas operacionais ao parentesco bacteriano mais próximo (identidade $\geq 99 \%$ ).

\section{Tratamento dos dados}

Utilizou-se o software Statistica 7.0 (STATSOFT, Inc.) para a realização das análises de variância e análises de componentes principais (ACP). A ACP foi usada para descrever as correlações entre as variáveis que caracterizam a biomassa granular aeróbia, medidas ao longo das três estratégias operacionais. Foram escolhidas sete variáveis físico-químicas: $\mathrm{DQO}_{\mathrm{S}}$ (após o enchimento), temperatura, concentração de PN e PS, razão $\mathrm{IVL}_{30} / \mathrm{IVL}_{10}$, concentração de SSV no licor misto e a razão da $\mathrm{DQO}_{\mathrm{S}}$ removida na fase aeróbia pela $\mathrm{DQO}_{\mathrm{s}}$ removida na fase anóxica ( $\mathrm{DQO}_{\mathrm{s}}$ efluente/ $\mathrm{DQO}_{\mathrm{s}}$ anóxico). O número de observações foi igual para todas as variáveis $(n=10)$ e a verificação da distribuição normal dos dados foi realizada a partir do teste de Shapiro-Wilk, considerando um intervalo de confiança de 95\% (IC95\%) (SHAPIRO; WILK, 1965). 


\section{RESULTADOS E DISCUSSÃO}

\section{Características físico-químicas dos grânulos}

A evolução da concentração de biomassa no reator está apresentada na Figura 2. Inicialmente, o lodo que não apresentava boa sedimentabilidade foi eliminado do sistema por wash out, chegando a $380 \mathrm{mg} \mathrm{SSV.L} \mathrm{L}^{-1}$ aos 43 dias de operação. Em seguida, houve acúmulo de biomassa no reator, alcançando $1.740 \mathrm{mg} \mathrm{SSV.L} \mathrm{L}^{-1}$ aos 132 dias de operação. Ao longo da segunda estratégia, observou-se uma tendência de diminuição da concentração de biomassa, a qual permaneceu entre 700 e 1.200 mg SSV.L $L^{-1}$ até o fim do período experimental. A menor variabilidade de concentração de sólidos ocorreu na estratégia III. Resultados semelhantes aos do presente estudo foram obtidos por Liu, Moy e Tay (2007),

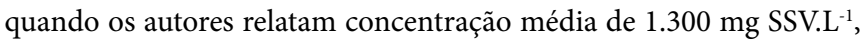

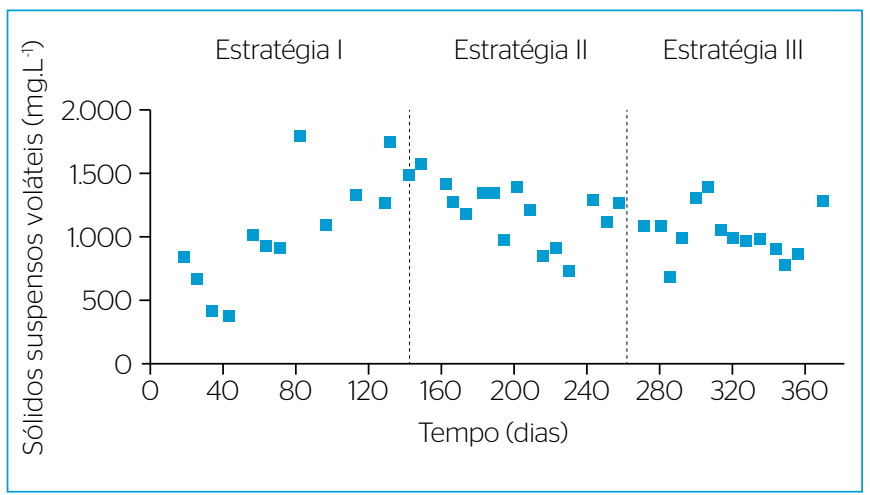

Figura 2 - Concentração de sólidos suspensos voláteis ao longo das estratégias operacionais. depois de operar durante 70 dias um RBS previamente inoculado com biomassa granular e alimentado com esgoto sanitário.

A distribuição dos tamanhos das partículas durante as três estratégias operacionais estudadas está apresentada na Figura 3. Inicialmente, todas as partículas apresentavam diâmetro menor que $200 \mu \mathrm{m}$. A partir do décimo sexto dia, $46 \%$ da biomassa apresentou diâmetro superior a $600 \mu \mathrm{m}$ e acima de $200 \mu \mathrm{m}$ somavam $83 \%$ da fração total. Porém, foram observadas variações na distribuição do tamanho das partículas ao longo das três estratégias. De acordo com de Kreuk et al. (2007), a biomassa é predominantemente granular quando os agregados apresentam diâmetro $>200 \mu \mathrm{m}$. Dessa forma, observa-se que o lodo foi considerado granular durante as estratégias I e III. Entretanto, os mesmos autores ressaltam que além do diâmetro das partículas, outras características físico-químicas, como IVL e EPS, devem ser consideradas em sistemas granulares.

As características de sedimentabilidade do lodo estão apresentadas na Figura 4. Durante a estratégia I, os valores de $I_{V L}, I V L_{10}$ e IVL demonstraram as maiores oscilações. A grande variabilidade observada tanto na concentração de sólidos como no tamanho dos agregados e no IVL pode ser atribuída à instabilidade da biomassa, pois o processo de granulação é gradual e segue três estágios consecutivos: aclimatação do lodo, agregação do lodo e maturação dos grânulos (WANG et al., 2005). Durante a estratégia II, observou-se que a diferença entre os resultados de IVL diminuiu, caracterizando a melhora da sedimentabilidade da biomassa. A razão $\mathrm{IVL}_{30} / \mathrm{IVL}_{10}$ para esse período permaneceu em 0,8 até o dia 230, indicando estabilidade estrutural dos grânulos e maior compacidade da biomassa, mesmo com as variações de concentrações de biomassa no reator (Figura 2).

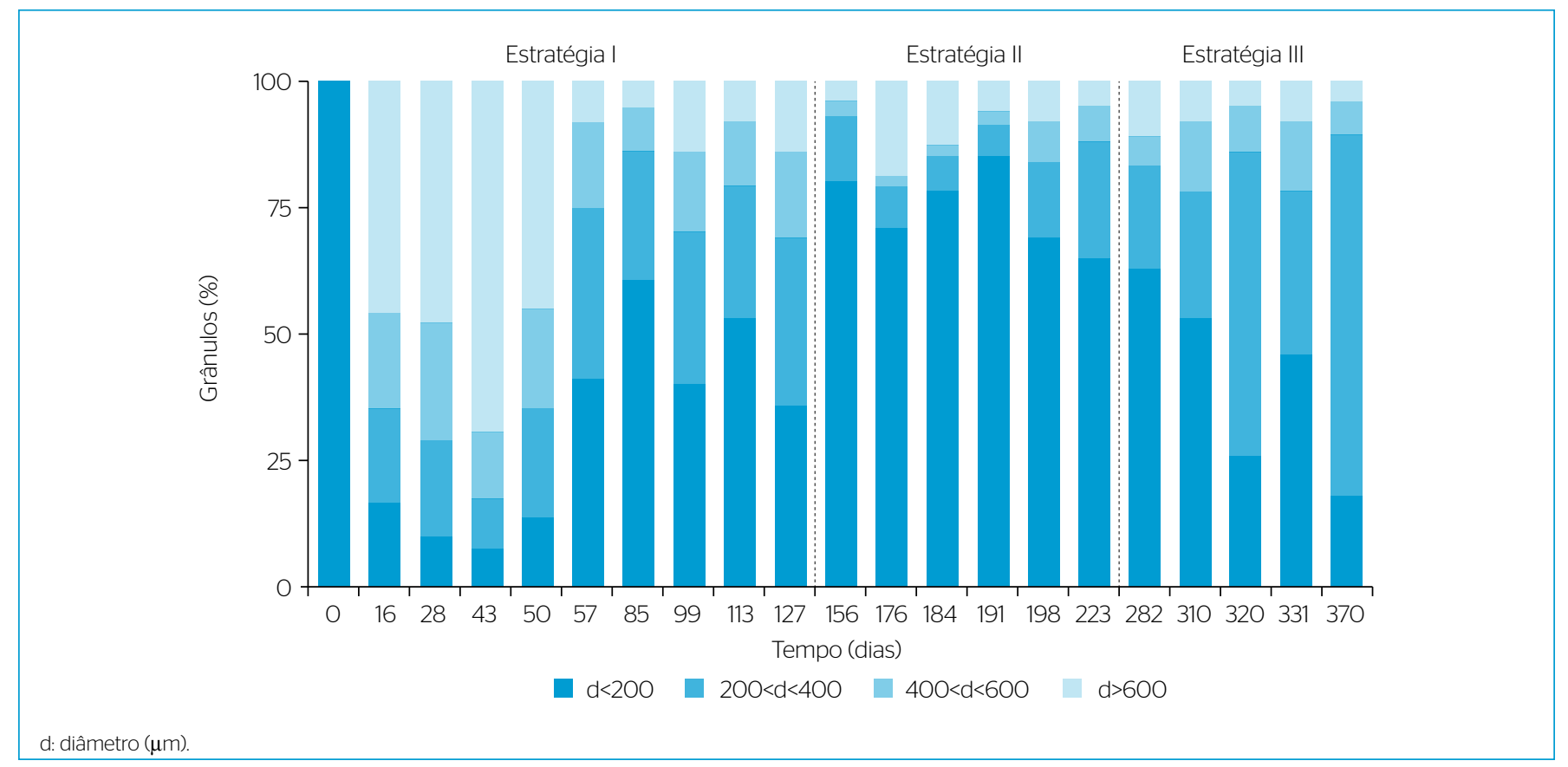

Figura 3 - Distribuição dos tamanhos das partículas ao longo das diferentes condições operacionais. 
Ao longo da estratégia III, na qual a proporção de período anóxico foi maior, os valores de $\mathrm{IVL}_{5}, \mathrm{IVL}_{10}$ e $\mathrm{IVL}_{30}$ se aproximaram consideravelmente, e a razão $\mathrm{IVL}_{30} / \mathrm{IVL}_{10}$ ficou próxima a 0,9; atingindo 1,0 aos 286 e aos 356 dias de operação (Figura 4). De acordo com de Kreuk et al. (2007), a razão $\mathrm{IVL}_{30} / \mathrm{IVL}_{10}$ fornece uma excelente indicação da formação de grânulos aeróbios. Quanto mais próximos os valores de $\mathrm{IVL}_{30} \mathrm{IVL}_{10}$, melhores a sedimentação e a compacidade do grânulo. Segundo Liu e Tay (2007), essa razão ainda informa sobre o processo de granulação. Para os autores, quando essa atinge 0,9 ; a granulação pode ser considerada completa. Portanto, no presente trabalho nota-se que, mesmo com a diminuição do diâmetro dos grânulos nas estratégias II e III, as características de sedimentabilidade e compacidade melhoraram. De acordo com Liu e Tay (2007), o maior tamanho do grânulo não garante a melhor capacidade de sedimentação, e o IVL é estreitamente relacionado com a densidade do lodo. Dessa forma, a granulação aeróbia não deve ser restrita apenas ao aumento do tamanho dos grânulos, mas também com base na compacidade e na capacidade de sedimentação da biomassa.

$\mathrm{Na}$ Tabela 1 estão apresentados os resultados de PN e PS durante as três estratégias operacionais. Observa-se que a maior produção de PN ocorreu durante a estratégia I, enquanto a de PS ocorreu na estratégia III. Nota-se que, ao longo das estratégias, há tendência de redução da razão PN/PS, em função do aumento da fração de PS e diminuição de PN. Resultados semelhantes aos do presente estudo foram obtidas por Zhu et al. (2015) e Liu et al. (2015). Os autores relataram valores médios PN/PS de 3,3 e 2,5; respectivamente.

A produção de matriz polimérica pode influenciar a floculação e a granulação de lodos, principalmente alterando as suas propriedades superficiais, tais como a carga superficial e a hidrofobicidade (WANG et al., 2006). No presente estudo, a estabilidade constatada no sistema durante a estratégia III pode ser atribuída ao fato de ter maior produção de PS (145 mg PS.g-1 SSV). Alguns autores afirmaram que a proporção de PS em relação às PN aumentou consideravelmente no processo de granulação, pelo fato dos PS serem os principais responsáveis pela estabilização mecânica dos grânulos (ADAV \& LEE, 2008). Igualmente, Zhang, Zhang e Yang (2015) atribuíram a formação de grânulos estáveis a maiores produções de PS. Dessa forma, além do tamanho das partículas, o EPS e o IVL demonstraram ser importantes na caracterização da biomassa granular aeróbia. Em termos operacionais, o presente estudo apontou melhor estabilidade da biomassa granular sob condição de maior tempo de ciclo e maior fração de período anóxico.

\section{Desempenho do reator}

Os resultados obtidos em relação à remoção de $\mathrm{DQO}_{\mathrm{S}}$ estão apresentados na Figura 5. Observa-se que mesmo com flutuações na $\mathrm{DQO}_{\mathrm{s}}$ afluente, a concentração média do efluente do sistema não apresentou grandes variações. Na estratégia I, a eficiência de remoção da $\mathrm{DQO}_{\mathrm{s}}$ não foi influenciada pela instabilidade inicial do reator. A eficiência de remoção durante essa estratégia apresentou valores próximos a $80 \%$, com concentração média efluente de $52 \mathrm{mg}$. $\mathrm{L}^{-1}$. Já na estratégia II, a eficiência de remoção média foi de $70 \%$, com concentração média efluente de $50 \mathrm{mg} \cdot \mathrm{L}^{-1}$. Ao longo da terceira estratégia, o percentual de eficiência de remoção se manteve estável, com média de $68 \%$ e concentração média efluente de 55 mg.L $\mathrm{L}^{-1}$.

Tabela 1 - Concentração de proteínas e polissacarídeos durantes as três estratégias operacionais.

\begin{tabular}{l|c|c|c}
\multirow{2}{*}{ Parâmetro } & Estratégia I & Estratégia II & Estratégia III \\
\cline { 2 - 4 } & \multicolumn{2}{|c|}{ média \pm desvio padrão (número de observações) } \\
\hline mg PN.g ${ }^{-1}$ SSV & $304 \pm 54(10)$ & $226 \pm 33(15)$ & $277 \pm 31(14)$ \\
\hline mg PS.g ${ }^{-1}$ SSV & $118 \pm 23(10)$ & $94 \pm 15(15)$ & $145 \pm 19(14)$ \\
\hline PN/PS & $2,61 \pm 0,35$ & $2,48 \pm 0,63$ & $1,93 \pm 0,25$ \\
\hline
\end{tabular}

PN: proteínas; SSV: sólidos suspensos voláteis; PS: polissacarídeos.

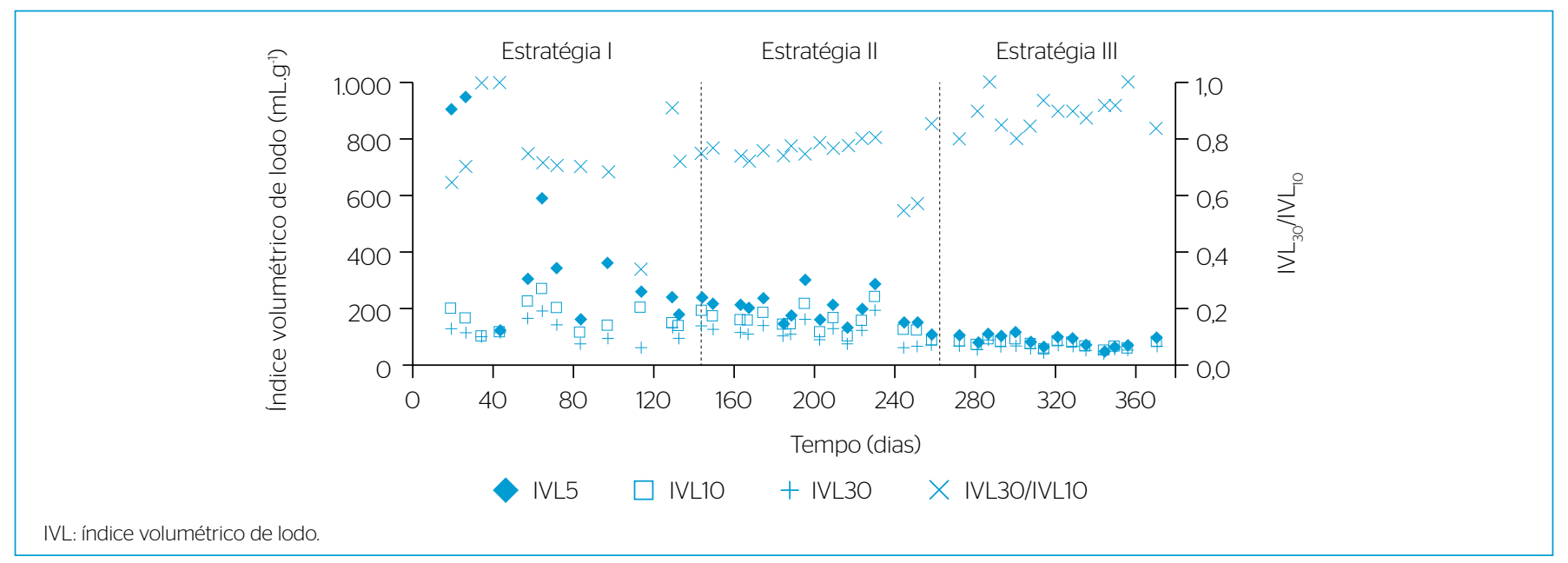

Figura 4 - Sedimentabilidade do lodo ao longo das três estratégias operacionais. 
Além da DQOs, a remoção de carbono foi avaliada em termos de $\mathrm{DBO}_{5}$. Assim como a DQOs, a $\mathrm{DBO}_{5}$ afluente (Tabela 2) apresentou grande variação ao longo do período operacional. Essa flutuação era esperada, visto que o estudo foi conduzido em condições reais tratando esgoto sanitário. Um aumento na eficiência de remoção da $\mathrm{DBO}_{5}$ foi observado ao longo do tempo. Para as estratégias I, II e III, foram obtidas eficiências de 69, 76 e 86\% com concentrações finais de 106; 70 e $31 \mathrm{mg} . \mathrm{L}^{-1}$, respectivamente. De acordo com a legislação nacional vigente (CONAMA 430 (BRASIL, 2011), os efluentes das três diferentes condições operacionais atenderam aos padrões de lançamentos referentes à remoção de matéria orgânica (<120 mg. $\mathrm{L}^{-1}$ ou $60 \%$ de remoção).

Em relação ao material particulado, as eficiências de remoção foram avaliadas por meio dos SST. Na primeira estratégia, após 70 dias de operação do reator, a eficiência de remoção média de SST foi de $64 \%$, com concentração de saída de $59 \mathrm{mg} . \mathrm{L}^{-1}$. Nas estratégias II e III, a remoção média foi de 80 e 55\%, com concentrações finais de 35 e $61 \mathrm{mg} . \mathrm{L}^{-1}$, respectivamente.

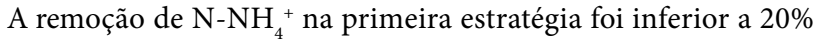
durante os primeiros dias ( 0 até 80 ), com pouca nitrificação do afluente. No entanto, a partir do dia 80 , observou-se aumento da remoção média para 56\%. A nitrificação aumentou na estratégia II, com eficiência de remoção média de 57\%, e foi mais estável e efetiva ao longo da terceira estratégia, onde a remoção média foi de $84 \%$. As concentrações médias de $\mathrm{N}-\mathrm{NH}_{4}^{+}$efluente para as estratégias I, II e III foram 24; 20 e 8 mg.L $\mathrm{L}^{-1}$, respectivamente. Durante os primeiros 80 dias, as concentrações de $\mathrm{N}-\mathrm{NH}_{4}^{+}$obtidas no efluente não atenderam à legislação brasileira para lançamento de efluentes em corpos receptores ( $\left.\leq 20 \mathrm{mg} . \mathrm{L}^{-1}\right)$. Como relatado por Li e Wu (2014), a baixa velocidade de nitrificação pode ser explicada pelo fato de que os microrganismos nitrificantes (autotróficos) crescem lentamente. Segundo os autores, um longo tempo de retenção de sólidos é necessário para manter esses organismos e, assim, assegurar a eficiência do processo de nitrificação. Além disso, segundo Szabó et al. (2016), as baixas eficiências de remoção de nutrientes obtidas durante a partida do reator são consequências do processo de lavagem da biomassa (wash out). Como discutido anteriormente, durante a estratégia I, houve uma diminuição da concentração de sólidos, por causa da "lavagem" da biomassa, apresentada na Figura 2.

A remoção biológica de fósforo pode ocorrer através dos organismos acumuladores de fósforo, os quais se desenvolvem sob condições de alternância de períodos anóxicos/aeróbios nos ciclos operacionais

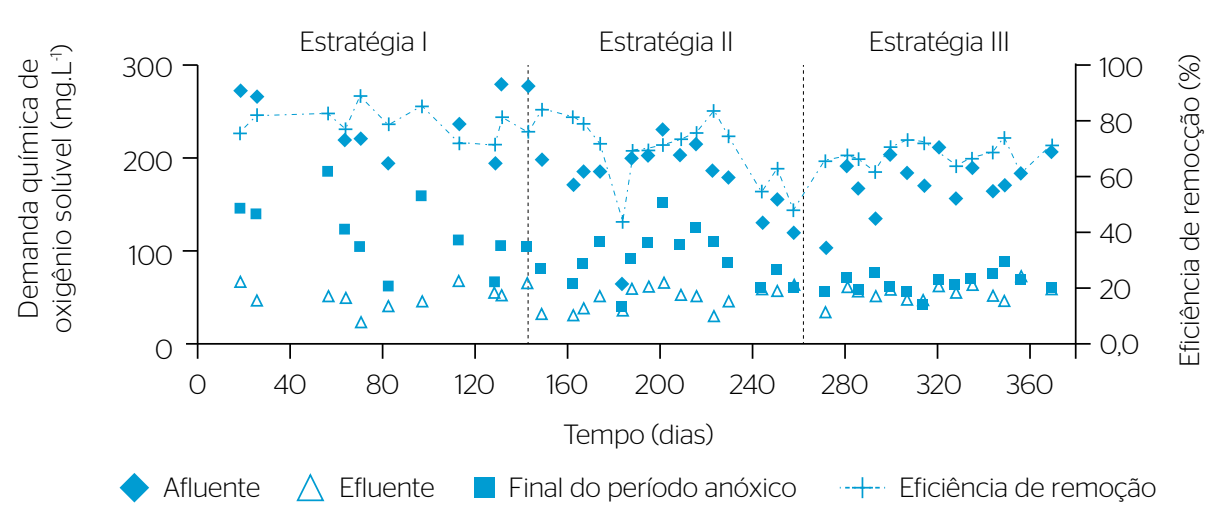

Figura 5 - Concentração de demanda química de oxigênio solúvel do afluente, final do período anóxico e efluente, e respectivas eficiências de remoção.

Tabela 2 - Características de entrada e saída do sistema, ao longo das estratégias operacionais.

\begin{tabular}{|c|c|c|c|c|c|c|}
\hline & \multicolumn{2}{|c|}{$\begin{array}{c}\text { Estratégia I } \\
\text { Duração=143 dias; } n=10\end{array}$} & \multicolumn{2}{|c|}{$\begin{array}{c}\text { Estratégia II } \\
\text { Duração=143 dias; n=15 }\end{array}$} & \multicolumn{2}{|c|}{$\begin{array}{c}\text { Estratégia III } \\
\text { Duração=108 dias; n=14 }\end{array}$} \\
\hline & Afluente (mg. $\left.\mathrm{L}^{-1}\right)$ & Efluente (mg. $\left.\mathrm{L}^{-1}\right)$ & Afluente (mg. $\left.\mathrm{L}^{-1}\right)$ & Efluente (mg. $\left.\mathrm{L}^{-1}\right)$ & Afluente (mg. $\left.\mathrm{L}^{-1}\right)$ & Efluente (mg. $\left.\mathrm{L}^{-1}\right)$ \\
\hline & \multicolumn{6}{|c|}{ (média士desvio padrão) } \\
\hline $\mathrm{DBO}_{5}$ & $334 \pm 60$ & $106 \pm 31$ & $290 \pm 95$ & $70 \pm 28$ & $221 \pm 36$ & $31 \pm 7$ \\
\hline SST & $162 \pm 35^{(1)}$ & $59 \pm 30^{(1)}$ & $216 \pm 102$ & $35 \pm 15$ & $145 \pm 48$ & $61 \pm 12$ \\
\hline $\mathrm{N}-\mathrm{NH}_{4}^{+}$ & $50 \pm 8^{(1)}$ & $24 \pm 12^{(1)}$ & $47 \pm 9$ & $20 \pm 11$ & $49 \pm 10$ & $8 \pm 5$ \\
\hline $\mathrm{PO}_{4}^{3-}-\mathrm{P}$ & $3,3 \pm 0,7$ & $2,4 \pm 0,6$ & $2,8 \pm 1,1$ & $2,0 \pm 0,9$ & $3,9 \pm 0,8$ & $3,4 \pm 1,0$ \\
\hline $\mathrm{pH}$ & $6,6 \pm 0,4$ & & $7,1 \pm 0,1$ & & $7,0 \pm 0,1$ & \\
\hline Temperatura ( $\left.{ }^{\circ} \mathrm{C}\right)$ & $21 \pm 2$ & & $23 \pm 2$ & & $26 \pm 1$ & \\
\hline
\end{tabular}

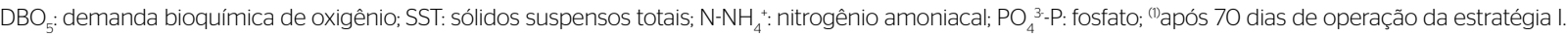


(DE KREUK \& VAN LOOSDRECHT, 2004). O esgoto bruto apresentou baixa concentração de fosfato (média $<4 \mathrm{mg} \mathrm{P}-\mathrm{PO}_{4}^{3-} \cdot \mathrm{L}^{-1}$ ) durante todo o período experimental. As eficiências de remoção de $\mathrm{P}_{-} \mathrm{PO}_{4}^{3-}$ durante as estratégias I, II e III foram de 19; 29 e 18\%, com concentrações finais de 2,4; 2,0 e 3,4 mg P- $\mathrm{PO}_{4}^{3-}$, respectivamente. Não há legislação nacional de enquadramento do fósforo nos padrões de lançamento em corpos hídricos. No entanto, de acordo com a Lei estadual $\mathrm{n}^{\circ}$ 14.675/2009, que institui o Código Estadual de Meio Ambiente de Santa Catarina, o valor máximo permitido para lançamento de fósforo total é de $4 \mathrm{mg} . \mathrm{L}^{-1}$ para ambientes lênticos, ou $75 \%$ de eficiência de remoção no caso de tratamento biológico (CONSEMA-SC, 2009).

\section{Comunidade microbiana}

A comunidade microbiana relacionada com a remoção de nitrogênio e fósforo foi avaliada no presente estudo por meio da técnica de FISH. Com relação aos organismos autotróficos, as bactérias oxidadoras de amônio (BOA) do gênero Nitrossomonas apresentaram baixa abundância inicialmente, correspondendo à baixa atividade de nitrificação na estratégia I. Um aumento gradual na abundância de BOA foi observado nas estratégias II e III, correlacionando com as melhores eficiências de remoção de $\mathrm{N}_{-} \mathrm{NH}_{4}{ }^{+}$. Para as bactérias oxidadoras de nitrito (BON), baixa abundância do gênero Nitrospira sp. foi detectada em todos os períodos experimentais, confirmando a baixa atividade de oxidação de nitrito durante todas as estratégias operacionais (dado não mostrado). Resultados semelhantes de predominância de BOA sobre BON foram também encontrados em outros estudos de cultivo de grânulos com esgoto sanitário (WAGNER et al., 2015; GUIMARÃES et al., 2017).

Com relação aos organismos heterotróficos, as bactérias desnitrificantes do gênero Pseudomonas sp. foram identificadas durante as estratégias I e III. Esses microrganismos se classificam como heterotróficos ordinários (ordinary heterotrophic organisms - $\mathrm{OHO}$ ) de rápido crescimento (NIELSEN et al., 2010). Os organismos heterotróficos de crescimento lento, como os $\mathrm{PAO}$, não foram identificados na estratégia I, enquanto algumas colônias foram observadas nas estratégias II e III. Mesmo observando diferenças na comunidade removedora de fósforo ao longo das estratégias, os resultados físico-químicos não demonstraram consideráveis diferenças nas eficiências de remoção de fósforo. Além de ter favorecido a ocorrência de PAO, a condição operacional III também favoreceu os organismos acumuladores de glicogênio (GAO). Esses organismos competem com PAO pelo consumo da matéria orgânica sob condições anaeróbias/anóxicas, o que pode ter prejudicado a biodesfosfatação nesse período (LOPEZ-VAZQUEZ et al., 2009; BASSIN et al., 2012).

A dinâmica microbiana caracterizada pelo sequenciamento de nova geração está demonstrada em termos de família na Figura 6. Durante a primeira estratégia (dias 64 e 83), as famílias mais abundantes foram Caulobacteraceae, Sphingomonadaceae, Pseudomonadaceae e Rhodocyclaceae. Na estratégia II (dia 189), destaca-se a família Comamonadaceae, com abundância relativa de
$22 \%$, enquanto na estratégia III (dias 293 e 391) a família Xanthomonadaceae predominou com $45 \%$. Notou-se que ao longo das estratégias estudadas houve redução na abundância relativa da família Pseudomonadaceae (gênero Pseudomonas sp.), enquanto observou-se o favorecimento da Xanthomonadaceae (gênero Pseudoxanthomonas sp.). Importante salientar que ambas as populações são desnitrificantes (NIELSEN et al., 2010), entretanto as Pseudoxanthomnas sp. destacam-se por serem produtoras de EPS (WEISSBRODT; SHANI; HOLLIGER, 2014), fundamentais na estrutura de microagregados. Esse resultado corrobora a melhor estabilidade do sistema, em termos de características da biomassa granular, obtida no fim do período operacional (estratégia III).

Em geral, os resultados de biologia molecular demonstraram a predominância das bactérias aeróbias heterotróficas de rápido crescimento em todas as estratégias. Contudo, os organismos de crescimento lento (BOA, PAO, GAO) nas estratégias II e III podem ter contribuído para as melhores características do lodo granular nesses períodos. De acordo com de Kreuk e van Loosdrecht (2004), esses organismos tornam a biomassa granular mais instável, enquanto a seleção de bactérias com velocidade de crescimento lento melhora a estabilidade dos grânulos. Dessa forma, o aumento do tempo de duração da fase anóxica do ciclo contribuiu para o consumo da matéria orgânica sob condições anaeróbias/anóxicas, permitindo o aparecimento de PAO e GAO, melhorando assim as características de sedimentabilidade e compacidade do lodo.

De acordo com Liu, Yang e Tay (2004), a densidade específica tem sido comumente usada para descrever a compacidade estrutural e a

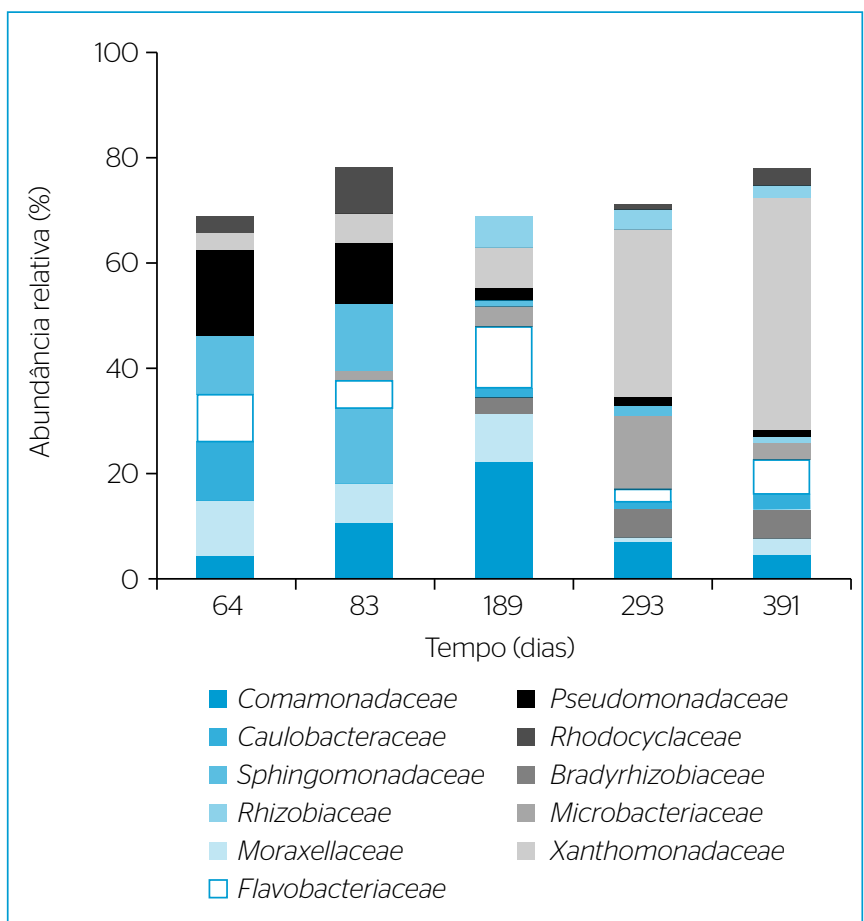

Figura 6 - Diversidade microbiológica em nível de família. A abundância relativa foi calculada considerando somente os microrganismos que apresentavam número de sequência maior que $5 \%$ do total da amostra. 
estabilidade de uma comunidade microbiana. A velocidade de crescimento reduzida resulta em um menor tamanho dos grânulos aeróbios, porém com maior densidade específica, indicando uma estrutura microbiana compacta e forte. Os autores ainda afirmam que há relação direta entre a densidade específica e o tamanho médio dos grânulos aeróbios, e ainda mostram que os grânulos grandes têm estrutura menos compactas. Tal observação é consistente com as encontradas em biofilmes, isto é, a compacidade do biofilme seria reduzida à medida que os biofilmes se tornam espessos. Dessa forma, os grânulos aeróbios com baixa velocidade de crescimento têm uma estrutura mais forte, isto é, a estabilidade estrutural dos grânulos aeróbios pode ser significativamente melhorada através da seleção de bactérias de crescimento lento.

\section{Análise estatística}

A ACP é uma ferramenta com resposta rápida e numérica que aponta as correlações entre as variáveis dentro de um conjunto de dados. A interpretação do arranjo das correlações entre as variáveis permite a detecção e a distinção de uma condição operativa normal, desejável ao processo, de uma operação instável indesejável. Durante a operação de um sistema real de tratamento de esgoto, variações na carga orgânica afluente ou nas características físico-químicas do esgoto afluente são esperadas. O gestor da estação de tratamento de efluentes (ETE) pode, portanto, utilizar a ACP para identificar qual aspecto (qualidade do afluente ou condição operacional incluída na análise) provocou a instabilidade (anormalidade) da operação do sistema de tratamento.
Dessa forma, a ACP foi aplicada no presente estudo para reduzir o espaço multidimensional, favorecendo a interpretação da correlação existente entre as variáveis escolhidas na análise, considerando o espaço modelado formado pelas componentes principais, preservando a máxima variabilidade dos dados possível. Na Figura 7 estão apresentados o score plot (A) e o loading plot (B), formados pela primeira $\mathrm{e}$ segunda componentes principais (CP1 e CP2, respectivamente). A CP1 apresentou $37 \%$ de representação da variação dos dados, e a CP2 representou $32 \%$, enquanto a representatividade dos demais fatores foi em torno de $30 \%$. Dessa forma, a duas principais componentes apresentam boa representatividade dos dados (cerca de 70\%).

Nota-se que, no score plot (Figura 7A), três diferentes clusters foram organizados, caracterizando as três estratégias operacionais desenvolvidas neste estudo. É importante observar que os scores foram descritivos na tendência da condição de estabilidade do sistema, isto é, o modo de arranjo de cada resultado individual (score) obtido retrata uma característica do funcionamento do reator com lodo granular ao longo do período experimental. Quando os dados da estratégia I foram aplicados ao modelo, os scores foram espaçadamente projetados, ocupando uma grande área (linha azul escuro), o que denota menor semelhança entre si, consequentemente maior variabilidade durante esse período. Tais evidências são típicas de um sistema em estado transiente, comumente encontrado em reatores durante o start up. Já na estratégia II, observa-se que os dados foram projetados no espaço modelado com maior proximidade entre si, caracterizando um sistema com maior estabilidade e menor variabilidade dos resultados obtidos (linha azul claro). De fato, essa evidência associa-se com o

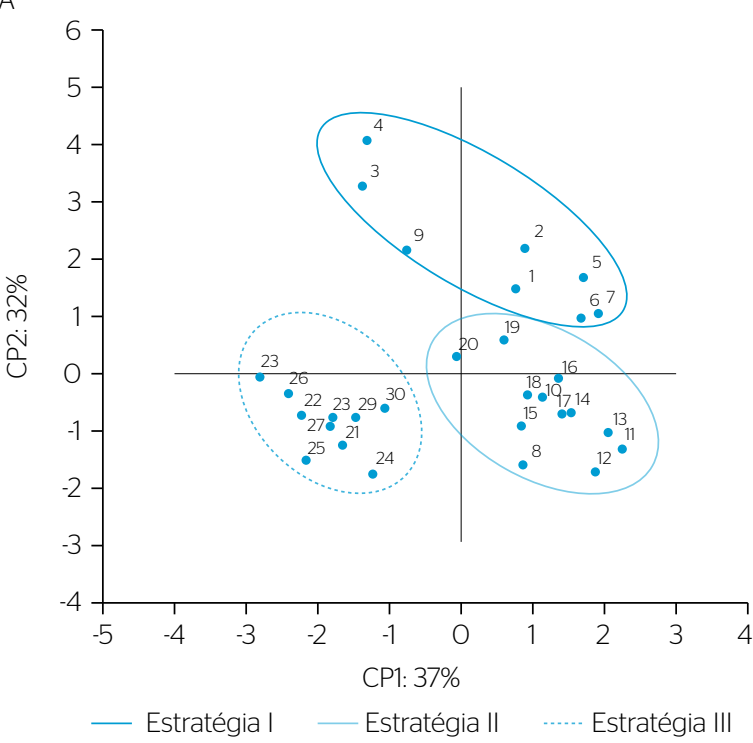

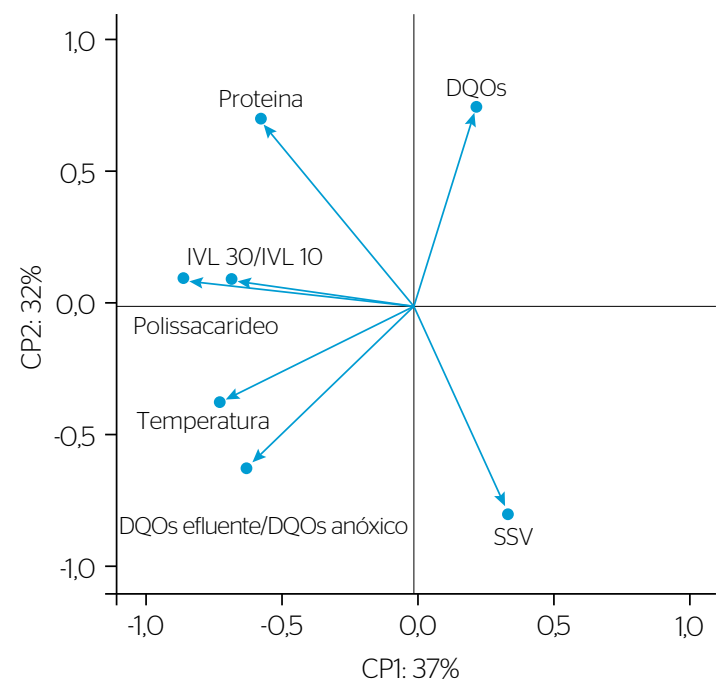

CP: componente principal; $\mathrm{DQO}_{\mathrm{s}}$ efluente/DQO anóxico: razão entre a demanda química de oxigênio solúvel do efluente e do anóxico; $I V L_{30} / I V L_{10}$ : razão entre os índices volumétricos do lodo após 30 e 10 minutos; SSV: sólidos suspensos voláteis.

Figura 7 - Score plot (A) e loading plot (B) para o modelo da análise de componentes principais. 
melhoramento do IVL e da concentração de SSV (Figura 4 e Figura 2). Verifica-se, portanto, que o agrupamento dos scores, nesse período, reflete o comportamento univariado dos dados de input da ACP. Um maior agrupamento dos dados foi observado para os scores do período da estratégia III. Esses foram projetados na menor área obtida durante o estudo (linha pontilhada), o que denota reduzida variabilidade dos dados em relação aos fatores (variáveis) estudados. O comportamento observado durante a estratégia III ressalta o regime de estado estacionário obtido no reator com lodo granular, condição estável de funcionamento do processo biológico.

Analisando-se a dispersão dos scores obtidos durante a operação do reator com lodo granular ao longo de todas as estratégias, verifica-se mudança de comportamento no padrão da variabilidade dos dados, especificamente de uma condição de maior instabilidade operacional (estratégia I, linha azul escuro) para maior estabilidade do processo (estratégia III, linha pontilhada). A dispersão dos dados da estratégia II (linha azul claro) representa a condição de transição entre os extremos já mencionados.

Através da análise conjunta score e loading plots, Figuras 7A e 7B, observa-se que durante a estratégia I, as variáveis que mais influenciaram o desempenho do reator foram a concentração de $\mathrm{DQO}_{\mathrm{S}}$ após o enchimento do reator e a concentração de PN do licor misto. Ambos os parâmetros tiveram os maiores valores comparados com as outras estratégias, $252 \mathrm{mg} . \mathrm{L}^{-1}$ e $304 \mathrm{mg}$ PN.g ${ }^{-1}$ SSV, respectivamente. No entanto, a concentração de biomassa do sistema influenciou de forma inversa os dados no espaço modelado, uma vez que nos primeiros 40 dias de operação ocorreu o fenômeno de wash out da biomassa. Já na estratégia II, a variável que influenciou o comportamento dos dados foi o SSV, e nessa condição a PN foi a variável que interviu de forma oposta. A concentração de biomassa obtida durante essa estratégia apresentou maior média (1.200 $\left.\mathrm{mg} \mathrm{SSV.L}^{-1}\right)$ e a concentração de PN foi menor nesse período (226 mg PN.g-1 SSV). Os dados projetados no espaço modelado da estratégia III foram fortemente influenciados pelo conjunto das variáveis: razão $\mathrm{IVL}_{30} / \mathrm{IVL}_{10}$, PS, temperatura e também a razão $\mathrm{DQO}_{\mathrm{S}}$ efluente/ $\mathrm{DQO}_{\mathrm{S}}$ anóxico, que é a proporção de remoção da DQO da fase aerada do ciclo em relação à remoção na fase anóxica.

A remoção de $\mathrm{DQO}_{\mathrm{S}}$ na fase anóxica foi total em praticamente todo o período da estratégia III (Figura 5). Uma vez que a $\mathrm{DQO}_{S}$ foi mínima na fase aeróbia durante essa estratégia, ocorreu melhoria na sedimentabilidade dos grânulos por conta do controle da proliferação das bactérias de crescimento rápido, que, de acordo com Zhang, Zhang e Yang (2015) e de Kreuk e van Loosdrecht (2004), interferem negativamente na estabilidade dos grânulos aeróbios. Essa evidência é corroborada pela análise dos scores durante a estratégia III (Figura 7A), os quais demonstram elevada correlação entre si, e cujas projeções estão agrupadas na região de influência das variáveis $\mathrm{IVL}_{30} / \mathrm{IVL}_{10}$ (média de 0,90), concentração de PS (média de 145 mg PS.g-1 SSV) e temperatura, que se manteve acima de $26^{\circ} \mathrm{C}$ (Figura $7 \mathrm{~B}$ e Tabela 2 ).

Em termos práticos, o controle do consumo da DQOs (sob condição anaeróbia/anóxica) é possível através da gestão do ciclo operacional. Dessa forma, os organismos favorecidos (heterotróficos de crescimento lento como $\mathrm{PAO} / \mathrm{GAO}$ ) formam grânulos mais estáveis e densos, em função dos PS e da matriz de EPS que produzem. Consequentemente, a sedimentabilidade do lodo (IVL) é melhorada, além do desempenho do sistema reator com lodo granular, uma vez que esses organismos também podem promover a remoção de fósforo.

\section{CONCLUSÕES}

Grânulos foram naturalmente formados com diâmetro médio de $600 \mu \mathrm{m}$, ao longo de 16 dias operacionais a partir do esgoto sanitário, dispensando a inoculação do reator com lodo biológico. As características do lodo granular aeróbio, em termos de sedimentabilidade e compacidade, foram melhoradas com o aumento da fase anóxica. A maturação dos grânulos foi de aproximadamente 80 dias $(200<$ diâmetro $<400 \mu \mathrm{m}$ ), com a predominância de microrganismos heterotróficos de rápido crescimento, família Xanthomonadaceae. O reator com lodo granular foi eficiente na remoção da matéria orgânica carbonácea e de nutrientes do esgoto sanitário, atendendo à legislação para lançamento de efluentes em corpos hídricos. A ACP evidenciou que as variáveis de maior relevância no processo foram a razão $\mathrm{IVL}_{30} /$ $\mathrm{IVL}_{10}$ e $\mathrm{DQO}_{\mathrm{S}}$ efluente/DQO ${ }_{\mathrm{S}}$ anóxico, PS e temperatura, indicando a importância desses parâmetros para a manutenção da estabilidade operacional de um reator com lodo granular.

\section{REFERÊNCIAS}

ADAV, S.S.; LEE, D.J. (2008) Extraction of extracellular polymeric substances from aerobic granule with compact interior structure. Journal of Hazardous Materials, v. 154, p. 1120-1126. https://doi. org/10.1016/j.jhazmat.2007.11.058

AMANN, R. (1995) In situ identification of microorganism by whole cell hybridization with rRNA-targeted nucleic acid probes.
In: AKKERMAN, A.D.L.; VAN ELSAS, J.D.; DE BRUIJN, F.J. (Orgs.). Molecular microbial Ecology Manual. p. 1-15.

AMERICAN PUBLIC HEALTH ASSOCIATION (APHA); AMERICAN WATER WORKS ASSOCIATION (AWWA); WATER ENVIRONMENT FEDERATION (WEF). (2005) Standard methods for the examination of water and wastewater. 21. ed. Washington, D.C.: APHA, AWWA, WEF. 
BASSIN, J.P.; KLEEREBEZEM, R.; DEZOTTI, M.; VAN LOOSDRECHT, M.C.M. (2012) Measuring biomass specific ammonium, nitrite and phosphate uptake rates in aerobic granular sludge. Chemosphere, v. 89, n. 10, p. 1161-1168. https://doi.org/10.1016/j. chemosphere.2012.07.050

BIN, Z.; ZHE, C.; ZHIGANG, Q.; MIN, J.; ZHIQIANG, C.; ZHAOLI, C.; JUNWEN, L.; XUAN, W.; JINGFENG, W. (2O11) Dynamic and distribution of ammonia-oxidizing bacteria communities during sludge granulation in an anaerobic-aerobic sequencing batch reactor. Water Research, v. 45, n. 18, p. 6207-6216. https://doi. org/10.1016/j.watres.2011.09.026

BRASIL. Conselho Nacional do Meio Ambiente (CONAMA). (2011) Resolução CONAMA no 430/2011. Diário Oficial da União, p. 8.

CARTA, F.; BEUN, J.J.; VAN LOOSDRECHT, M.C.M.; HEIJNEN, J.J. (2OO1) Simultaneous storage and degradation of $\mathrm{PHB}$ and glycogen in activated sludge cultures. Water Research, v. 35, n. 11, p. 2693-2701.

CONSELHO ESTADUAL DO MEIO AMBIENTE DE SANTA CATARINA (CONSEMA-SC). (2009) Leino14.675, de 13.04.2009-Instituio Código Estadual do Meio Ambiente e estabelece outras providências. Brasil.

DE KREUK, M.K.; KISHIDA, N.; VAN LOOSDRECHT, M.C.M. (2007) Aerobic granular sludge - state of the art. Water Science and Technology, v. 55, n. 8-9, p. 75-81. https://doi.org/10.2166/wst.2007.244

DE KREUK, M.K.; VAN LOOSDRECHT, M.C.M. (2004) Selection of slow growing organisms as a means for improving aerobic granular sludge stability. Water Science and Technology, v. 49, n. 11-12, p. 9-17.

DUBOIS, M.; GILLES, K.A.; HAMILTON, J.K.; REBERS, P.A.; SMITH, F. (1956) Colorimetric method for determination of sugars and related substances. Analytical Chemistry, v. 28, n. 3, p. 350-356. https://doi.org/10.1021/ac60111a017

GREUTER, D.; LOY, A.; HORN, M.; RATTEI, T. (2016) probeBase-an online resource for rRNA-targeted oligonucleotide probes and primers: new features. Nucleic Acids Research, v. 44, p. D586-D589. https://doi.org/10.1093/nar/gkv1232

GUIMARÃES, L.B.; MEZZARI, M.P.; DAUDT, G.C.; COSTA, R.H.R. (2O17) Microbial pathways of nitrogen removal in aerobic granular sludge treating domestic wastewater. Journal of Chemical Technology \& Biotechnology, v. 92, p. 1756-1765. https://doi.org/10.1002/jctb.5176

LI, B.; WU, G. (2014) Effects of sludge retention times on nutrient removal and nitrous oxide emission in biological nutrient removal processes. International Journal of Environmental Research and Public Health, v. 11, n. 4, p. 3553-3569. https://dx.doi. org/10.3390\%2Fijerph110403553

LIU, Y.; KANG, X.; LI, X.; YUAN, Y. (2015) Performance of aerobic granular sludge in a sequencing batch bioreactor for slaughterhouse wastewater treatment. Bioresource Technology, v. 190, p. 487-491. https://doi.org/10.1016/j.biortech.2015.03.008

LIU, Y.; YANG, S.F.; TAY, J.H. (2004) Improved stability of aerobic granules by selecting slow-growing nitrifying bacteria. Journal of Biotechnology, v. 108, n. 2, p. 161-169.
LIU, Y.Q.; MOY, B.Y.P.; TAY, J.H. (2007) COD removal and nitrification of low-strength domestic wastewater in aerobic granular sludge sequencing batch reactors. Enzymeand Microbial Technology, v. 42, n. 1, p. 23-28. http://dx.doi.org/10.1016/j.enzmictec.2007.07.020

LIU, Y.Q.; TAY, J.H. (2007) Influence of cycle time on kinetic behaviors of steady-state aerobic granules in sequencing batch reactors. Enzyme and Microbial Technology, v. 41, n. 4, p. 516-522. http://dx.doi.org/10.1016/j.enzmictec.2007.04.005

LOPEZ-VAZQUEZ, C.M.; HOOIJMANS, C.M.; BRDJANOVIC, D; GIJZEN, H.J.; VAN LOOSDRECHT, M.C. (2009) Temperature effects on glycogen accumulating organisms. Water Research, v. 43, n. 11, p. 2852-2864. https://doi.org/10.1016/j.watres.2009.03.038

LOWRY, O.H.; ROSEBROUGH, N.J.; FARR, A.L.; RANDALL, R.J. (1951) Protein measurement with the Folin phenol reagent. Journal of Biological Chemistry, v. 193, n. 1, p. 265-275.

MCSWAIN, B.S.; IRVINE, R.L.; HAUSNER, M.; WILDERER, P.A. (2005) Composition and distribution of extracellular polymeric substances in aerobic flocs and granular sludge. Applied and Environmental Microbiology, v. 71, n. 2, p. 1051-1057. https://doi. org/10.1128/AEM.71.2.1051-1057.2005

MOGHADDAM, S.S.; MOGHADDAM, M.A. (2015) Cultivation of aerobic granules under different pre-anaerobic reaction times in sequencing batch reactors. Separation and Purification Technology, v. 142, p. 149-154. https://doi.org/10.1016/j. seppur.2014.12.046

MORGENROTH, E.; SHERDEN, T.; VAN LOOSDRECHT, M.C.M.; HEIJNEN, J.J.; WILDERER, P.A. (1997) Aerobic granular sludge in a sequencing batch reactor. Water Research, v. 31, n. 12, p. 3191-3194. https://doi.org/10.1016/S0043-1354(97)00216-9

NIELSEN, P.H.; MIELCZAREK, A.T.; KRAGELUND, C.; NIELSEN, J.L.; SAUNDERS, A.M.; KONG, Y.; HANSEN, A.A.; VOLLERTSEN, J. (2010) A conceptual ecosystem model of microbial communities in enhanced biological phosphorus removal plants. Water Research, v. 44, n. 17, p. 5070-5088. https://doi.org/10.1016/j. watres.2010.07.036

PRONK, M.; DE KREUK, M.K.; DE BRUIN, B.; KAMMINGA, P.; KLEEREBEZEM, R.; VAN LOOSDRECHT, M.C.M. (2015) Full scale performance of the aerobic granular sludge process for sewage treatment. Water Research, v. 84, p. 207-217. https://doi.org/10.1016/j. watres.2015.07.011

SARMA, S.J.; TAY, J.H.; CHU, A. (2017) Finding Knowledge Gaps in Aerobic Granulation Technology. Trends in Biotechnology, v. 35, n. 1, p. 66-78. https://doi.org/10.1016/j.tibtech.2016.07.003

SHAPIRO, S.S.; WILK M.B. (1965) An analysis of Variance test for Normality (Complete Samples). BioMetrika, v. 52, p. 591-611. https:// doi.org/10.2307/2333709

SZABÓ, E.; HERMANSSON, M.; MODIN, O.; PERSSON, F.WILÉN, B.M. (2016) Effects of Wash-Out Dynamics on Nitrifying Bacteria in Aerobic Granular Sludge During Start-Up at Gradually Decreased Settling Time. Water, v. 8, n. 5, p. 172. https://doi.org/10.3390/w8050172 
TAY, J.H.; LIU, Q.S.; LIU, Y. (2001) Microscopic observation of aerobic granulation in sequential aerobic sludge blanket reactor. Journal of Applied Microbiology, v. 91, n. 1, p. 168-175.

WAGNER, J.; GUIMARÃES, L.B.; AKABOCl, T.R.V.; COSTA, R.H.R. (2015) Aerobic granular sludge technology and nitrogen removal for domestic wastewater treatment. Water Science \& Technology, v. 71, n. 7, p. 1040-1046. https://doi.org/10.2166/wst.2015.064

WAN, C.; ZHANG, P.; LEE, D.J.; YANG, X.; LIU, X.; SUN, S.; PAN, X. (2O13) Disintegration of aerobic granules: role of second messenger cyclic di-GMP. Bioresource Technology, v. 146, p. 330-335. https:// doi.org/10.1016/j.biortech.2013.07.073

WANG, F.; YANG, F.L.; ZHANG, X.W.; LIU, Y.H.; ZHANG, H.M.; ZHOU, J. (2005) Effects of cycle time on properties of aerobic granules in sequencing batch airlift reactor. World Journal of Microbiology \& Biotechnology, v. 21, n. 8-9, p. 1379-1384. https://doi.org/10.1007/ s11274-005-5451-2

WANG, Z.; LIU, L.; YAO, J.; CAI, W. (2006) Effects of extracellular polymeric substances on aerobic granulation in sequencing batch reactors. Chemosphere, v. 63, n. 10, p. 1728-1735. https://doi. org/10.1016/j.chemosphere.2005.09.018

WEISSBRODT, D.G.; SHANI, N.; HOLLIGER, C. (2014) Linking bacterial population dynamics and nutrient removal in the granular sludge biofilm ecosystem engineered for wastewater treatment.
FEMS Microbiology Ecology, v. 88, n. 3, p. 579-595. https://doi. org/10.1111/1574-6941.12326

YANG, S.F.; TAY, J.H.; LIU, Y. (2003) A novel granular sludge sequencing batch reactor for removal of organic and nitrogen from wastewater. Journal of Biotechnology, v. 106, n. 1, p. 77-86. https://doi.org/10.1016/j.jbiotec.2003.07.007

ZHANG, C.; ZHANG, H.; YANG, F. (2015) Diameter control and stability maintenance of aerobic granular sludge in an A/O/A SBR. Separation and Purification Technology, v. 149, p. 362-369. http:// dx.doi.org/10.1016/j.seppur.2015.06.010

ZHENG, Y.M.; YU, H.Q.; SHENG, G.P. (2005) Physical and chemical characteristics of granular activated sludge from a sequencing batch airlift reactor. Process Biochemistry, v. 40, n. 2, p. 645-650. https://doi.org/10.1016/j.procbio.2004.01.056

ZHU, L.; DAI, X.; LV, M.; XU, X. (2013) Correlation analysis of major control factors for the formation and stabilization of aerobic granule. Environmental Science and Pollution Research, v. 20, n. 5 , p. 3165-3175. https://doi.org/10.1007/s11356-012-1202-8

ZHU, L.; ZHOU, J.; LV, M.; YU, H.; ZHAO, H.; XU, X. (2O15) Specific component comparison of extracellular polymeric substances (EPS) in flocs and granular sludge using EEM and SDSAGE. Chemosphere, v. 121, p. 26-32. https://doi.org/10.1016/j. chemosphere.2014.10.053 